\title{
Review paper on Design and Development of Muffler to Optimize Transmission Losses
}

\author{
Sandeep G Thorat", B S Kothavale, Swapnil S Hatwalane and Dhiraj Bhaskar \\ †Mechanical Engineering Department, MIT College of Engineering, Savitribai Phule Pune University, India \\ Accepted 02 March 2016, Available online 15 March 2016, Special Issue-4 (March 2016)
}

\begin{abstract}
New regulations and standards for noise reductions and emission compel the automobile industries to make some improvements in the design of silencer for attaining desired noise reduction. In this project, modifications are desired in the silencer design of upcoming Eicher tractor to fulfill the current standards. The current noise level at Operator Ear Level (OEL) is $97 \mathrm{~dB}$ (decibels), it is desired to reduce it to $94 \mathrm{~dB}$ and below. Also the maximum backpressure of 50 $\mathrm{mm}$ of $\mathrm{Hg}$ is to be maintained. New design should be analyzed with respect to both acoustics and back pressure. As per the various studies reactive mufflers with extended inlet and outlet pipes into muffler, which is not present in current design can significantly reduce the noise level. Helmholtz resonator can also be introduced to cancel the noise of dominating frequencies. Also a sound absorbing material like glass fibers and steel wool can be incorporated for better results. Further, the design modifications are to be verified for noise reduction by COMSOL Multi-physics software. Also the numerical results for transmission loss will be verified with experimentally measured results.
\end{abstract}

Keywords: Operator Ear Level (OEL), backpressure, mufflers, COMSOL Multiphysics, transmission loss

\section{Introduction}

In Indian agriculture industries, the role of tractors is very important. Often, they are used in various industries for much purpose. With high degree of use of these power sources, a safe and comfortable environment for the operators and other people becomes a major concern for productivity. Besides the physical exertion, one of the major discomforting factors is noise of the tractor. According to various studies the major noise causing elements in tractors are silencer, cooling fan, timing gear cover, oil pump and structural related noise. It is also observed that the sound pressure level (SPL) of the tractors is more than the ISO standards of 8 hrs,(Yadav P. S. Gaikwad A. A., Jan 2013). So as a part of this project it was desired to perform some modifications in current design of silencer so as to reduce noise level from primary level. Silencers are also known as mufflers. They are used for reducing the noise emitted from various sources like they are used extensively on the intake as well as exhaust systems of the reciprocating internal combustion engines, compressors, fans, blowers, gas turbines, the heating ventilation and air-conditioning (HVAC) systems, high-pressure vents and safety valves et al. Munjal. M. L. Designing for Quietness, PPT, Facility for Research in Technical Acoustics (FRITA)

*Corresponding author: Sandeep G Thorat
Amongst all the noise produced by automobiles are more harmful to humans and animals.

It becomes more vital in residential areas or areas where noise creates hazards. Generally, exposure for long time to noise level above $90 \mathrm{~dB}$ is injurious to heath(Subham Pal, Tejpreet Singh Golan et al (May Jun 2014).The design of exhaust mufflers is a critical part which requires the major concern and expertise. The design of muffler is based on different functional and aesthetical parameters. Where functional parameters include; type of muffler to be used, desired sound, adequate insertion loss, back pressure, temperature induced, size, cost, shape and style.

\section{Literature Survey}

Many researchers are working on acoustics of the automobile and persisting to improve the tuning of the silencer. It is observed that high noise level and unpleasant noise causes fatigue to human ear and reduces the efficiency of the workers. Various studies have been carried out with different dimensional combinations and altering the internal design of the mufflers. RavindranV. et al (2013), Discussed about various passive methods to control noise in agriculture tractors. He conducted experiments and found that the high frequency noise is generated from hydraulic pump, cooling fan, transmission and engine. 
Table 2.1 Noise amplitude level and source

\begin{tabular}{|c|c|c|}
\hline $\begin{array}{c}\text { Frequency } \\
\text { Band (Hz) }\end{array}$ & $\begin{array}{c}\text { Amplitude } \\
\text { (dBA) }\end{array}$ & Noise Source \\
\hline 160 & 76.0 & Engine \\
\hline 315 & 77.0 & Transmission \\
\hline 500 & 83.0 & Cooling fan \\
\hline 630 & 82.0 & Hydraulic Pump \\
\hline
\end{tabular}

In another study, Yadav P. S et al. (2013) conducted Noise Source Identification (NSI) Test for air born noise in tractor and found that silencer, hydraulic pump and timing gear are the major sources of noise. He performed design modification and structural optimization for noise reduction using CAE and successfully reduced noise by $6 \mathrm{dBA}($ Nazirkar. D. et al , June 2014).Subham Pal et al. (2014) made studies on tunable resonator whose length can be varied by piston mechanism. They conducted experiments at different positions of resonator to check the effect of variation of silencer length and found that it shows smaller resonator size along with better insertion losses. The advantages of tunable resonator type muffler are that it gives better attenuation with smaller size. On the negative side, these types of resonator mufflers are costly and best suited for frequency range between $250 \mathrm{~Hz}$ to $500 \mathrm{~Hz}$ et alSubham Pal, Tejpreet Singh Golan (May Jun 2014).

Rahul D. Nazirkar et al. optimized the simple single and double expansion chambers by using CATIA and ANSYS to find out the natural frequency of the muffler. The purpose of the study was to analyze the single and double expansion chamber performance and ability to avoid resonance. The concluded that the double expansion chamber gives better results as compared to single expansion chamber muffler. The natural frequency of the double expansion chamber was found more than the operating frequencies. Hence, double expansion chamber mufflers are more effective but also increase cost of manufacturing(Nazirkar. D. et al June 2014). Jin Woo Lee (2014) conducted design and experiment for finding the optimum topology of reactive muffler. The aim of the experiment was to optimize the muffler and making the partition volumes as small as possible (Takashi Yasuda, Chauqun $\mathrm{Wu}$, et al. June 2012).

ZeynepParlar et al. (2013) studied a reactive perforated muffler numerically and experimentally. The transmission loss for the muffler was analyzed using NASTRAN, ANSYS and COMSOL software. For experimental results he used FFT analyzer, pressure microphones, power amplifiers and sound source. He found that the results obtained by numerical analyses and experimentally were having an error of around $20 \%$. So, prior to prototype manufacturing the muffler design should be verified numerically,(ZeynepParlar, RifatYilmaz, et al 2013).

Takashi Yasuda et al. (2012) conducted research on muffler with low pass filter and Helmholtz resonator. He found that the interconnecting holes enabled the muffler to have a noise attenuation performance of Helmholtz resonator. Hence, such type of muffler can attenuate the low frequency as well as high frequencies at the same time. In his study he concluded that
- The chamber volume at both side of the return pipe should be equal to obtain a lowest cut-off frequency.

- The tail pipe should be as long as possible to attain lower cut-off frequency.

- Continuous holes should be located on the front of tail pipe for better attenuation of lower frequencies (Takashi Yasuda, Chauqun $\mathrm{Wu}$, et al.June

2012)

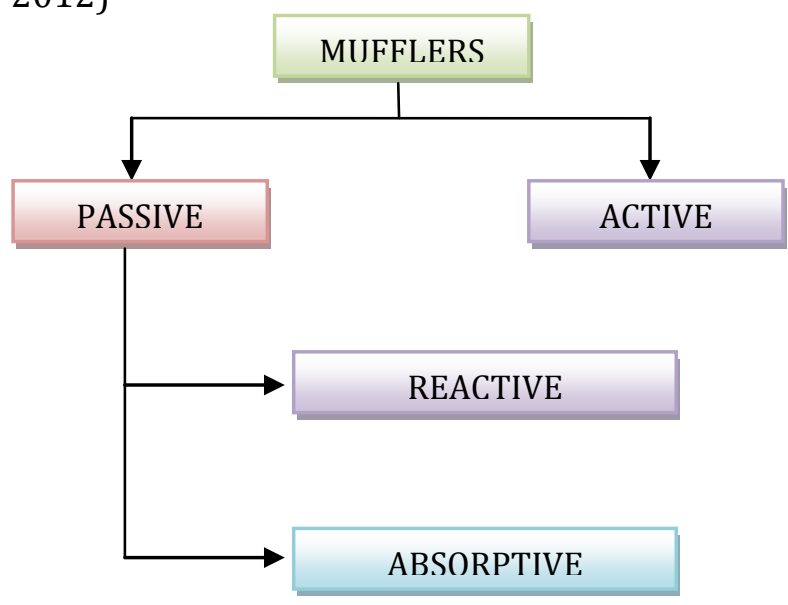

Fig.2.1 Types of Mufflers

\subsection{Classification of Mufflers}

Mufflers on the basis of functioning principal can be classified into two main types i.e. Active and Passive. The passive can be further classified in two types: Reactive (or reflective) and absorptive (or dissipative) Amongst these passive mufflers are widely used because of their easy and economic design ability. Further, reactive mufflers are most commonly used due to their easy manufacturing and cost effective.

\section{A. Active mufflers}

These mufflers are often used in large ducts where the external silencers are not possible.

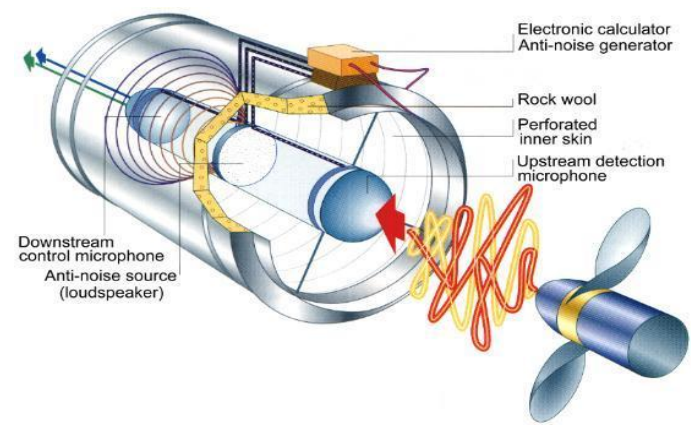

This uses the principal of impedance. The noise control in ducts consist of secondary source of noise and an adaptive digital control system which produces the same frequency noise to occur zero impedance at the junction. An active noise control system produces an acoustical short-circuit, effectively muffling the 
primary as well as secondary sources ofsound. It is most effective to damp low frequencies (50 to $500 \mathrm{~Hz}$ ) (Munjal, M. L.et $a l$ )

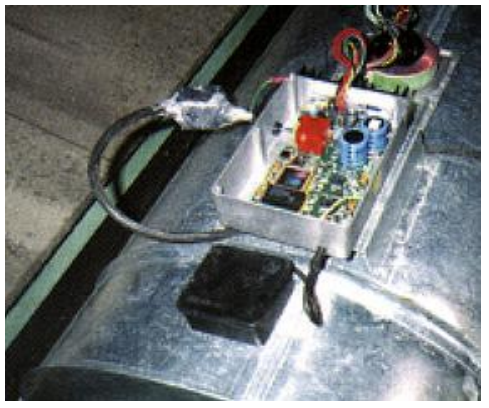

Fig 2.2 Active Mufflers

\section{Passive mufflers}

These mufflers do not use any secondary noise sources. Passive mufflers use the principal of reflection and absorption of noise. They are classified into two different types:

\section{B. Reactive (Reflective) mufflers}

These types of mufflers use the phenomenon of destructive interference to reduce noise. This is done by making sudden changes in cross section area, introducing perforated elements and resonators [3], The sound pulses generated from engine partially cancel themselves in the expansion chamber.

\section{Absorptive (dissipative) mufflers}

These types of mufflers do not reflect the noise, instead they uses a sound absorbing material. The sound absorbing material absorbs the sound energy and converts that energy into heat energy. Subham Pal, Tejpreet Singh Golan et al(May Jun 2014)

\subsection{Some Important Terms Related to Muffler Design}

\subsubsection{Sound Pressure Level (SPL)}

It is the logarithmic measure of the effective pressure of the sound to the reference value. The SPL is denoted by Lp and it unit is $\mathrm{dB}$ (decibels). Mathematically,

$L p=20 \log _{10}\left(\frac{p}{p o}\right)$

Where,

$\mathrm{P}=$ is root mean square sound pressure;

$\mathrm{P}_{\mathrm{o}}=$ is the reference sound pressure;

Commonly,

$\mathrm{P}_{\mathrm{o}}=200 \mu \mathrm{Pa}$

\subsubsection{Insertion Loss (IL)}

The IL is difference of sound pressure level measured at a point which is usually outside of the system, with and without muffler Nazirkar. D. Rahul, Meshram S. R.(1 June 2014)et al.

\subsubsection{Transmission loss (TL)}

It is the difference in the SPL between the incident entering wave and exiting wave transmitted through muffler when the muffler termination is anechoic. The TL is the property of muffler only (Nazirkar. D. Rahul, Meshram S. R. et al 2014)et al.

\subsubsection{Backpressure}

It is the pressure exerted on the exhaust valve and exhaust pipe of the engine due to developed pressure in muffler. The negative effect of high backpressure reduces efficiency resulting in a decrease of power output that must be compensated by increasing fuel consumption(Nazirkar. D. Rahul, Meshram S. R. et al1 June 2014).

\section{Silencer Design Methodology}

A good designed muffler should satisfy the least five following criteria. (Suganeswaran K., Parameshwaram R., Palanimohan D.et al(TAPSA-2014).

- The acoustic criteria: - which involves the minimum noise reduction required by the muffler as the function of frequency.

- The Aerodynamic criteria: - which specifies the maximum acceptable average pressure drop by the muffler at a given conditions of temperature and mass flow.

- Geometric Criteria: - which specifies the maximum allowable volume and shape restrictions.

- Mechanical criteria: - which specifies the mechanical demands like durability and less maintenance.

- Economic criteria: - which provides the cost of the product to the customer.

The muffler design technique involves 7 basic steps. The following fig shows the 7 required steps for a good muffler design.

\section{Step I : Target setting and Benchmarking}

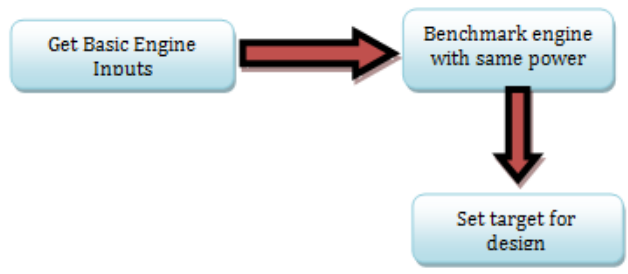

Step II:Calculate Target frequencies 


\section{Step III : Muffler Volume Calculations}

Refer the Engine basic Data

Calculate Muffler Volume

\section{Step IV : Internal Configuration and Concept Design}

।

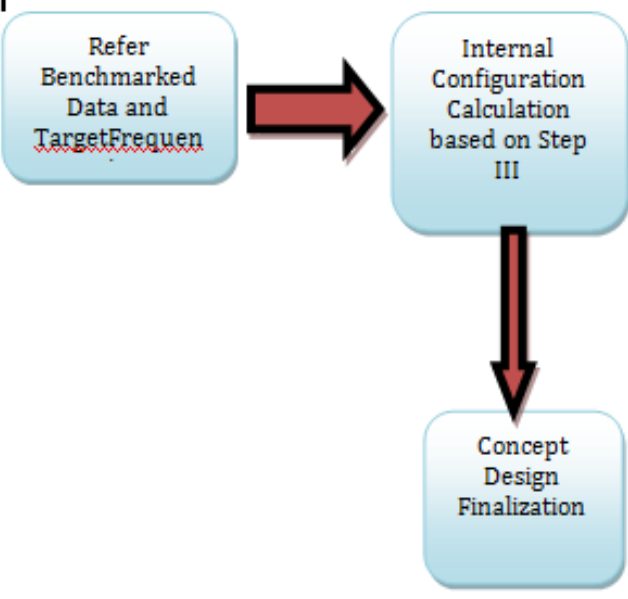

\section{Step V:Virtual Stimulations}

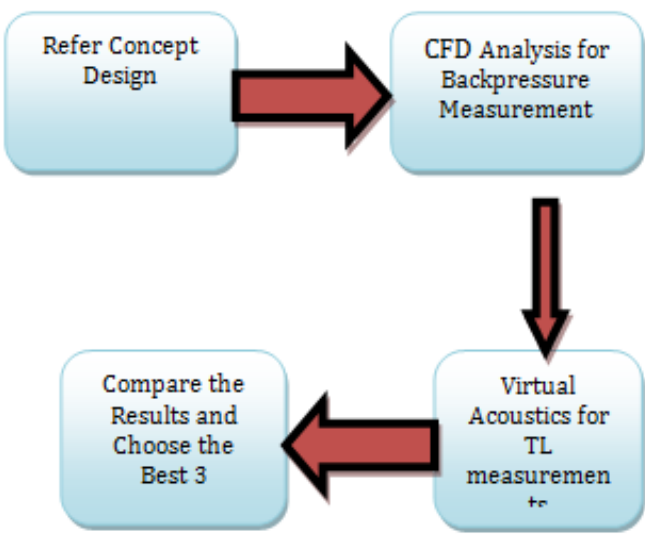

Step VI :Prototype Manufacturing

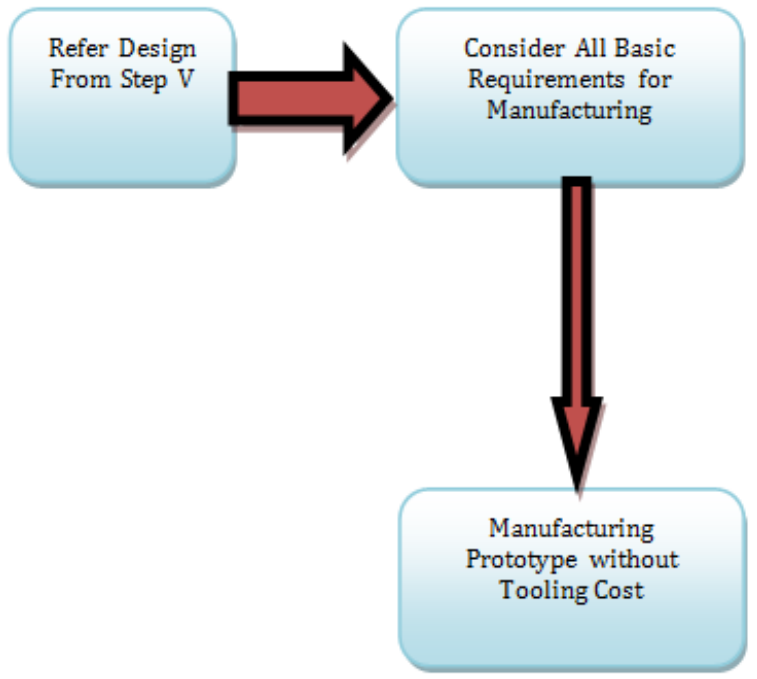

\section{Step VII: Experimental Testing and Design} Finalization of Prototype

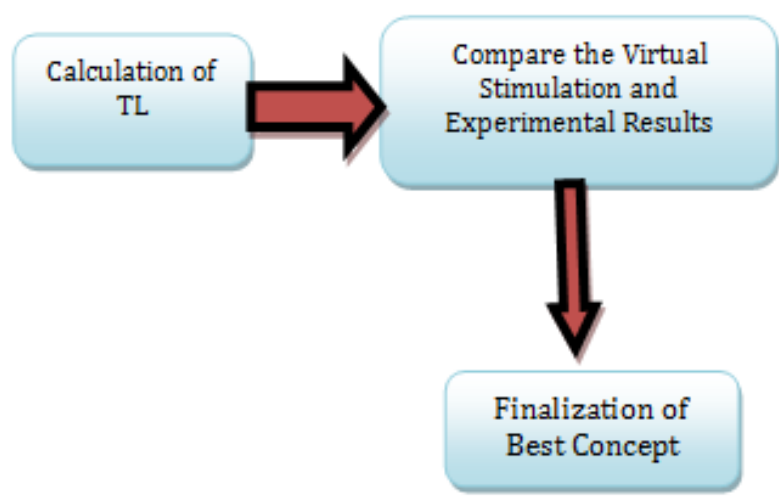

\section{STEP 1: Benchmarking}

This step is meant to set a target in terms of transmission loss in comparison to competitors in market or with respect to any standard parameters or company policy. Based on the provided engine input data and benchmark study target for back pressure and noise are range decided.

\section{STEP 2: Target Frequencies}

In this step the dominating frequencies calculate to give more concentration of higher transmission loss. For calculating the domination frequencies engine max power rpm is required and calculated by following formulae:

The exhaust tones are calculated using the following formulae:

\section{Cylinder Firing Rate}

CFR = Engine Speed in RPM $/ 60$

For a two stroke engine

= Engine Speed in RPM/120

For a four-stroke engine

\section{Engine Firing Rate}

$\mathrm{EFR}=\mathrm{n} \times(\mathrm{CFR})$

Where,

$\mathrm{n}=$ number of cylinders

\section{STEP 3: Volume of the Muffler}

Based theory of acoustics for muffler design for various engines, the following equation gives the solution for volume of muffler. 
Volume swept by each cylinder:

\section{Swept volume (Vs)}

$V S=\frac{\pi x D^{2} \times L}{4}$

Volume to be consider for calculation:

Volume $=n \times \frac{V s}{2}$

\section{Silencer volume}

Volume of silencer must be at least 12 to 25 times the volume considered. Volume can be adjusted depending on the space constraint

\section{Diameter of the muffler (d)}

$V m=\frac{\pi}{4}\left(d^{2} \times l\right)$

\section{STEP 4: Internal configuration and concept design}

Based on the benchmarking transmission loss and the target frequencies, designer draws few concepts of internal configuration that meets the packaging dimension within the volume mentioned above. Each concept and internal configuration is then formulated to the best possible configuration so as to achieve best acoustic performance and best (i.e. least) backpressure.

Perforations: Perforated pipe forms an important acoustic element of muffler, which is tuned in line with the dominating frequencies identified in step 2.The diameter of the hole to be drilled / punched on the pipe is calculated by:

$d 1=\frac{1.29}{\sqrt{N}}$

Porosity $(\sigma)$ is given by

$\sigma=\left(\left(\pi / 4 \times(d 1)^{\wedge} 2\right)\right) /\left(\left(c^{\wedge}(2)\right)\right)$

The open area ratio Aop is given by,

Aop $=($ Area of perforation / Area of the plain sheet $)$

Lesser the Aop better the transmission loss and better the acoustic performance. At this stage, the diameter of the hole to be drilled, pitch, number of holes per row, number of rows for each pattern of holes is frozen and hence, the distance at which perforation starts and at which the perforation ends also gets frozen. Thus, the design of the perforated tube for individual hole patterns is finalized. Based on this best concepts are designed and carry forward for virtual simulations.

\section{STEP 5: Virtual Simulation}

Based on above mentioned approach, different concepts will be arrived with optimum combinations of different elements inside volume of the silencer. Finalized concepts will be verified virtually using CAE simulation software's towards the achievement of transmission loss and back pressure.

\section{CFD Analysis}

When steady air flow passes through mufflers, there will have steady pressure drop which is related to flow and geometry of air passages. Pressure drop in an exhaust muffler plays an important role for the design and development of mufflers. Predication of pressure drop will be very useful for the design and development of muffler. To predict the pressure drop associated with the steady flow through the muffler CFD has developed over the last two decades. So the flow prediction can be made reliable Shital Shah, Saisankaranarayana K. at el(2010)

\section{Transmission loss analysis}

Prediction of transmission loss virtually is an important analysis required for the development of muffler at an initial design stage. There are different software packages available in market for predicting the transmission loss.

It is also to be noted the limitations of the CAE tools, as the co-relation at higher frequencies is difficult since the plane wave theory holds well only up to $3000 \mathrm{~Hz}$ beyond which the wave is no more 2 dimensional but 3 dimensional for which the computations are far complex to match the practical results. Hence need of research to blend both strengths of CAE \& Practical resulting in a Practical approach/methodology. After completion of simulation the best three concepts will (with less back pressure and higher transmission loss) be taken forward for the prototype manufacturing to check for the transmission loss and back pressure physically,Shital Shah, Saisankaranarayana K.(2010)

\section{STEP 6: Prototype manufacturing}

All the above stages combined with the packaging of the engine evolve the design of the prototype muffler can be taken up for manufactyring.

\section{STEP 7: Experimental testing and design finalization}

The experimental determination of backpressure of engine and transmission loss for different concepts is verified. The prototypes of all concepts that are made at the above step are tested for the transmission loss to verify the target value,Shital Shah, Saisankaranarayana K. (2010). Some other design considerations should be taken into consideration et alSubham Pal, Tejpreet Singh Golan (May Jun 2014). The mufflers with extended tube chambers have better attenuations than 
that of simple chambers.

- There is no significant difference between the insertion loss of a muffler with extended tube and that of muffler with reversal flow.

- More number of chambers more is the attenuation. But increases cost.

- Larger area of the chamber results in higher insertion loss.

3.1 Basic standards from ASHRAE Technical Committee Exhaust Muffler Grades

\begin{tabular}{|c|c|c|}
\hline \multicolumn{3}{|c|}{ Industrial/ commercial: } \\
\hline IL = 15 to $25 \mathrm{dBA}$ & $\begin{array}{c}\text { Body/Pipe }=2 \text { to } \\
2.5\end{array}$ & $\begin{array}{c}\text { Length/Pipe }=5 \\
\text { to } 6.5\end{array}$ \\
\hline \multicolumn{3}{|c|}{ Residential grade: } \\
\hline $\mathrm{IL}=20$ to $30 \mathrm{dBA}$ & $\begin{array}{c}\text { Body/Pipe }=2 \text { to } \\
2.5\end{array}$ & $\begin{array}{c}\text { Length/Pipe }=6 \\
\text { to } 10\end{array}$ \\
\hline \multicolumn{3}{|c|}{ Critical Grade: } \\
\hline $\mathrm{IL}=25$ to $35 \mathrm{dBA}$ & Body/Pipe $=3$ & $\begin{array}{c}\text { Length/Pipe }=8 \\
\text { to } 10\end{array}$ \\
\hline \multicolumn{3}{|c|}{ Super Critical Grade: } \\
\hline $\mathrm{IL}=35$ to $45 \mathrm{dBA}$ & Body/Pipe $=3$ & $\begin{array}{c}\text { Length/Pipe }=10 \\
\text { to } 16 .\end{array}$ \\
\hline
\end{tabular}

\subsection{Resonance Design}

Maximum attenuation occurs when

$\mathrm{L}=\mathrm{n} \lambda / 4$

Where,

$$
\begin{aligned}
& \lambda=\text { wave length of the dominating frequency } \\
& \lambda=V_{s} / f=\text { velocity of sound } / \text { frequency } \\
& \mathrm{n}=\text { odd integers. }
\end{aligned}
$$

\section{Expected Outcome}

On the basis of literature survey and studies, it is expected that the new muffler design would be a 3 chamber muffler with extended perforated tube. Further it would have a resonator to damp the most dominating frequencies. The total length of the silencer may be reduced to make it more cost effective.

\section{Scope}

- This will help to reduce noise level in upcoming tractor

- This will encourage the other automotive industries to work upon acoustics of vehicle and set up market for vehicles with least noise.

Reduced noise will provide ease to operators and workers and positively affect the productivity

\section{References}

Munjal, M. L. Designing for Quietness, PPT, Facility for Research in Technical Acoustics ( FRITA).

Subham Pal, Tejpreet Singh Golan (May Jun 2014), Design of a Muffler \& Effect of Resonator Length for 3 Cylinder SI Engine, IOSR-JMCE, , PP 85-91.

ZeynepParlar, RifatYilmaz,(27-03-2013), Acoustic and Flow Field Analysis of a Perforated Muffler Design, World Academy of Science, Engineering and Technology

Potente, Daniel, (9-11 Nov 2005), General Design Principles for an Automotive Muffler, Acoustics.

Yadav P. S. Gaikwad A. A., (9-12 Jan 2013), Noise Reduction on Agriculture Tractor, SAE internationals

Nazirkar. D. Rahul, Meshram S. R.(1 June 2014), Design \& optimization of Exhaust Muffler \& Design Validation, 10th IRF International Conference.

Suganeswaran K., Parameshwaram R., Palanimohan D. (TAPSA-2014), Design and Optimization of Muffler for Manufacturing, proc of Second National Conference on Trends in Automotive Parts Systems and Applications IJIRSET.

Shital Shah, Saisankaranarayana K. (2010) A Practical Approach towards Muffler Design, Development \& Prototype Validation, SAE international

Rahman M., Sharmin T. (2005), Design and Construction of A Muffler Engine Exhaust Noise Reduction, Proc of The International conference on Mechanical Engineering, Dhaka, , ICME05-TH-47

Ravindran V. (2013), Agricultural Tractor Noise Control, SAE international

Jin Woo Lee, (Aug 2013), Optimum Topology of Reactive muffler Achieving Target Transmission Loss value: Design and Experiment, Applied acoustics, Elsevier.

Takashi Yasuda, Chauqun Wu, et al. (June 2012), Studies on an Automobile Muffler with the Acoustic Characteristic of Low-Pass Filter and Helmholtz Resonator, Applied acoustics Elsevier. 